\title{
Therapeutic Strategies To Counteract Antibiotic Resistance in MRSA Biofilm-Associated Infections
}

Stella Cascioferro+ ${ }^{[a]}$ Daniela Carbone ${ }^{+},{ }^{[a]}$ Barbara Parrino, ${ }^{[a]}$ Camilla Pecoraro, ${ }^{[a]}$ Elisa Giovannetti, ${ }^{[b, c]}$ Girolamo Cirrincione, ${ }^{[a]}$ and Patrizia Diana*a]

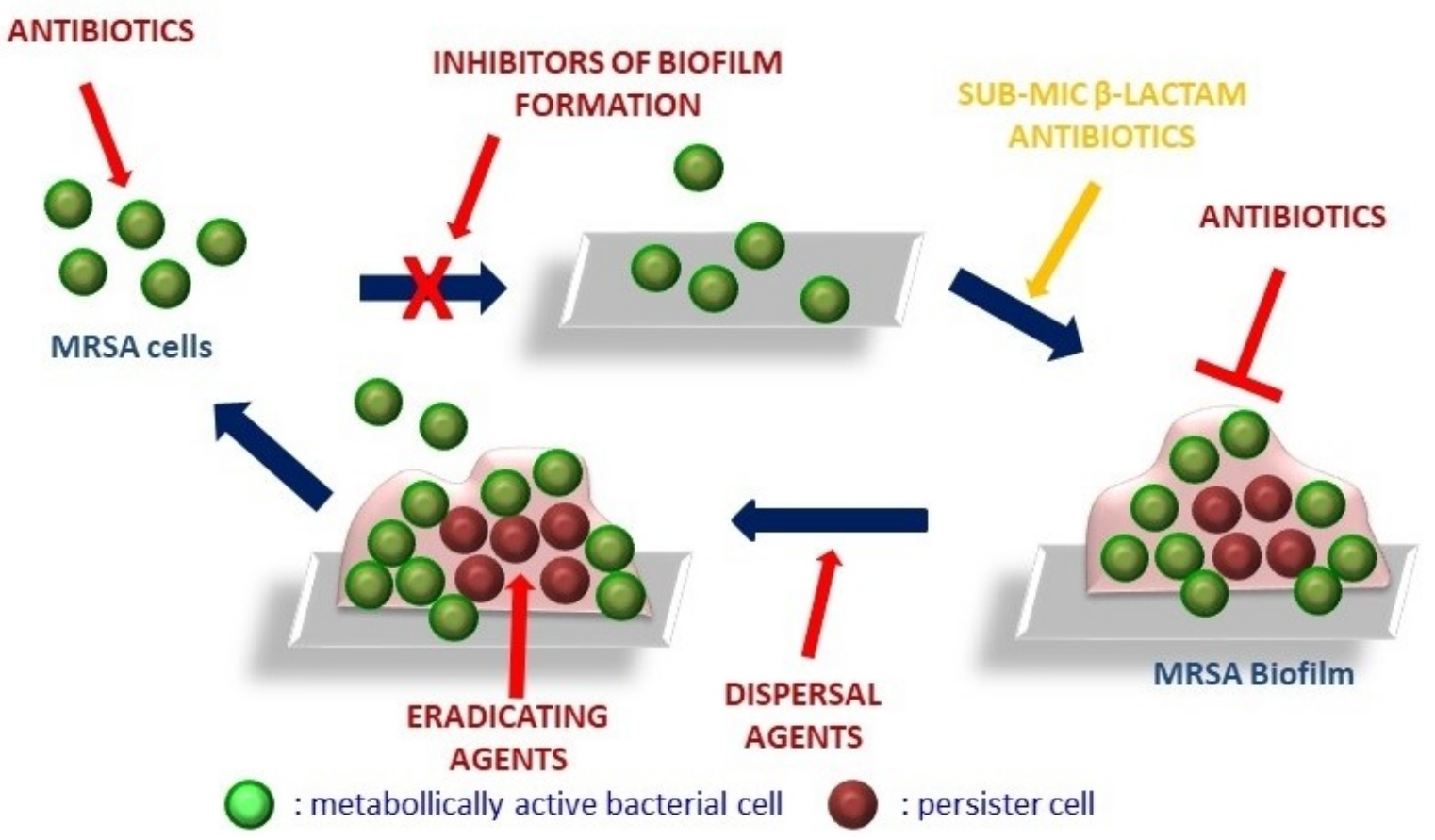


Methicillin-resistant Staphylococcus aureus (MRSA) has emerged as one of the leading causes of persistent human infections. This pathogen is widespread and is able to colonize asymptomatically about a third of the population, causing moderate to severe infections. It is currently considered the most common cause of nosocomial infections and one of the main causes of death in hospitalized patients. Due to its high morbidity and mortality rate and its ability to resist most antibiotics on the market, it has been termed a "superbug". Its ability to form biofilms on biotic and abiotic surfaces seems to be the primarily means of MRSA antibiotic resistance and pervasiveness. Importantly, more than $80 \%$ of bacterial infections are biofilm-

\section{Introduction}

Antibiotic-resistance (AMR) is among the most relevant health problems of this century. There is urgent need for new therapeutic strategies which are able to overcome the main bacterial resistance mechanisms. ${ }^{[1,2]}$

Staphylococcus aureus belongs to the ESKAPE family, which includes the nosocomial relevant pathogens Enterococcus faecalis, Klebsiella pneumoniae, Acinetobacter baumannii, Pseudomonas aeruginosa and Enterobacter sp.

Methicillin-resistant Staphylococcus aureus (MRSA) is one of the main causes of persistent human infections. Since MRSA is responsible for severe morbidity and mortality worldwide, in 2017 it has been categorized as a high priority multi-drug resistant (MDR) pathogen by the World Health Organization (WHO)

MRSA causes serious infections resistant to conventional antibiotic therapy, such as skin and soft tissue infections, bacteremia, infective endocarditis, osteomyelitis, and pneumonia. Moreover, MRSA is often responsible of indwelling catheter infections, prosthetic devices and implant associated infections. ${ }^{[3,4]}$ An important gene that confers to MRSA the capability to growth undisturbed in presence of penicillin-like antibiotics, is mecA gene, that is found in all MRSA strains and encodes the penicillin binding protein $2 \mathrm{a}$ (PBP2a). ${ }^{[5]}$ PBPs are membrane-bound enzymes, which play essential roles in cell

[a] Dr. S. Cascioferro, ${ }^{+}$Dr. D. Carbone, ${ }^{+}$Dr. B. Parrino, C. Pecoraro,

Prof. G. Cirrincione, Prof. P. Diana

Department of Biological, Chemical and Pharmaceutical Sciences and Technologies (STEBICEF)

University of Palermo

Via Archirafi 32

90123, Palermo (Italy)

E-mail: patrizia.diana@unipa.it

[b] Prof. E. Giovannetti

Department of Medical Oncology

Cancer Center Amsterdam

VU University Medical Center (VUmc)

De Boelelaan 1117

1081HV, Amsterdam (The Netherlands)

[c] Prof. E. Giovannetti

Cancer Pharmacology Lab, AIRC Start Up

Fondazione Pisana per la Scienza

Via Ferruccio Giovannini 13

56017, San Giuliano Terme, Pisa (Italy)

$\left.{ }^{[}{ }^{+}\right]$These authors contributed equally to this work. mediated. Biofilm formation on indwelling catheters, prosthetic devices and implants is recognized as the cause of serious chronic infections in hospital environments. In this review we discuss the most relevant literature of the last five years concerning the development of synthetic small molecules able to inhibit biofilm formation or to eradicate or disperse preformed biofilms in the fight against MRSA diseases. The aim is to provide guidelines for the development of new anti-virulence strategies based on the knowledge so far acquired, and, to identify the main flaws of this research field, which have hindered the generation of new market-approved anti-MRSA drugs that are able to act against biofilm-associated infections

wall biosynthesis catalysing the reactions involved in the synthesis of cross-linked peptidoglycan from lipid intermediates and allowing the removal of D-alanine residue from the precursor of peptidoglycan. ${ }^{[6]}$ The functionality of these enzymes, which is crucial for bacterial growth, cell division and cellular structure, was compromised by $\beta$-lactam antibiotics that cause irreparable damage to the bacterial cell wall and, consequently, the bacterial death ${ }^{[7]}$

In S. aureus four PBPs named PBP1, PBP2, PBP3, and PBP4 were found. MRSA, instead, showed an additional $P B P$, the PBP2a, that is the unique PBP that, despite shares the structural features to the other PBPs, is not inhibited by $\beta$-lactam antibiotics. $^{[8]}$

The major cause of the MRSA antibiotic resistance and pervasiveness is to be found in its ability to form biofilm on biotic and abiotic surfaces. Many factors are involved in MRSA biofilm resistance: first of all, the limitation of the antibiotic entrance due to the presence of the polymerizable mucopolysaccharide on the biofilm surface; moreover, the existence in the deepest layers of metabolically inactive cells, intrinsically resistant to antibiotics. Additionally the accumulation of bacterial cells within the biofilm facilitates the horizontal genetic transfer of the genes responsible for resistance.

Bacterial cells within the biofilm are extremely more resistant to antibiotics, as well as to host immune response, compared to the planktonic form of life.

In the last decade, many efforts have been made to identify new agents able to interfere with the staphylococcal biofilm life cycle, and many compounds showed interesting anti-biofilm activities, although none has reached the clinic. ${ }^{[9-15]}$ This is mainly due to very limited in vivo studies capable of confirming its activity.

Anti-biofilm compounds acting as anti-virulence agents, have the advantage over conventional antibiotics, to not affect bacterial growth and then, to impose a low selective pressure on the onset of antibiotic resistance mechanisms. ${ }^{[16]}$

Anti-biofilm agents can interfere with different steps of the development process, which leads from the planktonic form to the sessile phenotype. They can inhibit the biofilm formation, mainly interfering with the bacterial adhesion, or they can disrupt preformed biofilms dissolving matrix architecture. Additionally, some anti-biofilm agents are able to kill the persister cells of the deepest layers of the biofilm, eradicating it. 
Many bacterial processes can be considered valid targets for the development of new anti-biofilm agents such, for example, the quorum sensing (QS) system, which regulates the bacterial cell-to-cell signalling and the nucleotide second messenger signalling systems. It is recognized the key role of QS system in the coordination of the bacterial attachment and biofilm formation, as well as, in biofilm dispersion in response to changes in environmental conditions. ${ }^{[17]}$

Contrary to what is observed in other bacteria, in S. aureus QS system inhibits the biofilm formation through the production of matrix degrading enzymes such as protease, nuclease and lipase. This different role of QS system was confirmed by the robust biofilm production observed in a $S$. aureus strain deficient in the regulator gene agr, which encodes the two component regulatory system, TCRS. ${ }^{[18]}$

One of the biggest difficulties in finding valuable therapeutic strategy to treat MRSA biofilm associated infections is the existence of different staphylococcal biofilm phenotypes. ${ }^{[19]}$

While staphylococcal strains methicillin susceptible (MSSA) produce biofilms with a mechanism ica operon-mediated which involves $i c a A D B C$ genes in the production of polysaccharide intercellular adhesin (PIA) or polymeric $\mathrm{N}$-acetyl-glucosamine (PNAG), MRSA expresses a ica-independent biofilm formation
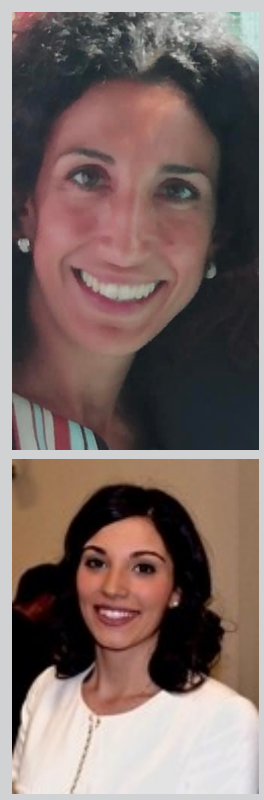

Stella Cascioferro graduated in Pharmacy with honors in 1999, and she got her Ph.D. in Medicinal Chemistry in 2004 at the University of Palermo. Her research interests include the design and the development of new heterocyclic compounds as antitumoral and antiinfective agents. Currently, she is researcher at the University of Palermo, Italy. She is the author of 66 scientific papers published in peer reviewed international journals of medicinal chemistry.

Daniela Carbone holds a master's degree in Pharmacy (full marks with honors) from the University of Palermo in 2015. From July to November 2018, she was a Ph.D. visiting student at VU University Medical Center of Amsterdam, and she earned her Ph.D. in Molecular and Biomolecular Sciences, with additional certification of Doctor Europaeus, in February 2019. Her current research interests are focused on the medicinal chemistry field, particularly the design, synthesis, and biological evaluation of heterocyclic compounds, analogues of natural marine alkaloids, with antitumor and anti-infective properties.

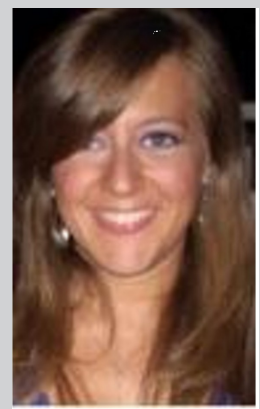

Barbara Parrino graduated in Medicinal Chemistry and Technology at the University of Palermo with full marks with honors in 2007. She got her Ph.D. in Pharmaceutical Sciences in March 2012. She received the "Doctor Europaeus" label. On September 2012, she was awarded the P. Ehrlich MedChem EuroPhD Network Certificate. In 2015 she was recipient of the Medicinal Chemistry Division of the Italian Chemical Society Prize. Currently, she is researcher at the University of Palermo and author of 62 papers and one Italian patent.

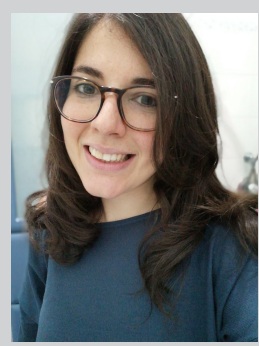

Camilla Pecoraro obtained her master degree in Chemistry and Pharmaceutical Technology with full marks and honors from the University of Palermo in 2018. She is currently working toward her Ph.D. degree in Molecular and Biomolecular Sciences. Her doctoral research is focused on design and synthesis of new heterocyclic compounds with antitumor activity. Her current research interests are in the field of medicinal chemistry with a special focus on analogs of natural marine alkaloids with antitumor and antibacterial activity.

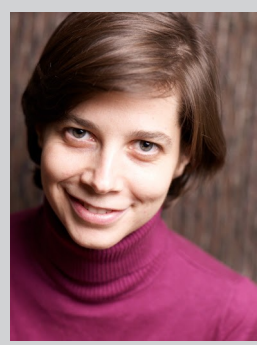

Elisa Giovannetti is associate Professor of Pharmacology at the VU University Medical Center, Amsterdam, and Principal Investigator at the Cancer Pharmacology Lab (University of Pisa). She is member of the Steering Committee of the Pharmacology and Molecular Mechanisms (PAMM) group of the EORTC, and her studies are funded by grants from Italian Association for Research against Cancer (AIRC), Netherlands Organization for Scientific Research (NWO), Cancer Center Amsterdam (CCA) Foundation, and Dutch Cancer Society (KWF).

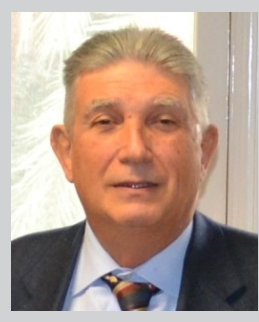

Girolamo Cirrincione is Emeritus Professor of Medicinal Chemistry at the University of Palermo. He is a member of the Drug Discovery Committee of the Pharmacology and Molecular Mechanisms (PAMM) Group of the European Organization for Research and Treatment of Cancer, the Italian Chemical Society, where he has been President of the Medicinal Chemistry Division, and the International Society of Heterocyclic Chemistry, where he served as vice president for $2004-$ 2005. He was Pro-rector for Research of the University of Palermo for 2015 - 2018.

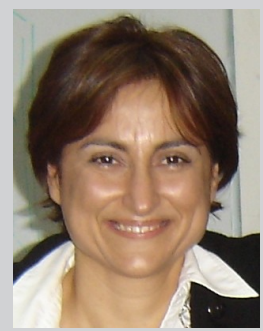

Patrizia Diana is full Professor of Medicina Chemistry at the University of Palermo. She is currently coordinator of the Medicinal and Biological Section of the Department of Science and Technology: Chemical, Biological and Pharmaceutical (STEBICEF) of the University of Palermo. She is a member of the Italian Chemical Society and International Society of Heterocyclic Chemistry and of the PAMM group of the ORTC. 
process contingent on the fibronectin binding proteins, FnBPA and FnBPB, and the major autolysin, Atl. ${ }^{[20,21]}$

In this review we focused on the recent development (20142020) of synthetic small molecules able to prevent biofilm formation or to interfere with pre-existing biofilms of the clinically relevant Gram-positive pathogen MRSA.

The understanding of the mechanisms of action, when reported, and of the SAR of the known anti-biofilm compounds can be a valuable guide for the development of new more potent anti-virulence agents able to counteract serious chronic MRSA biofilm-associated infections.

\section{MRSA biofilm development}

The bacterial adhesion to host tissue represents the first step of the biofilm formation as well as of the bacterial pathogenesis. ${ }^{[22]}$ In Gram-positive bacteria, the adhesion is mainly due to a class of surface proteins known as "microbial surface components recognizing adhesive matrix molecules" (MSCRAMMs). ${ }^{[23]}$ These proteins are structurally characterized by the presence of the common motif LPXTG (leucine, proline, any amino acid, threonine and glycine) which is recognized by the transpeptidase sortase A (SrtA). SrtA catalyses the anchoring of the MSCRAMMs to lipid II of the peptidoglycan through two consecutive reactions of thioesterification and transpeptidation. ${ }^{[2]}$ MSCRAMMs play key roles, in addition to adhesion, also in colonization and evasion of innate immune defences. Representative MSCRAMMs in $S$. aureus are the protein $A$ Spa, the fibronectin binding proteins FnbpA and FnbpB, the clumping factors ClfA and ClfB, the collagen-binding protein $C n a$, and the three serine aspartate repeat proteins SdrC, SdrD, and SdrE. ${ }^{[25]}$

After the primary attachment process to biotic or abiotic surfaces, bacterial cells start to proliferate and form microcolonies. Subsequently, an extracellular matrix is produced. ${ }^{[26]}$ It was found that $S$. aureus, as well as numerous Gram-positive pathogens, release extracellular polymeric substances (EPS), including extracellular proteins, lipids, extracellular DNA (eDNA) and polysaccharides, into the external environment during this phase of the biofilm formation. Among the polysaccharides, the PIA significantly contributes to the stability of the matrix structure of Gram-positive biofilms. In MRSA, differently from MSSA which showed a PIA-dependent biofilm formation, the most important mechanism of autoaggregation was the intracellular adhesion mediated by the eDNA derived from the autolysis of sessile and planktonic cells. ${ }^{[27]}$

During the last stage, known as maturation stage, microbial cells within the biofilm were released returning in planktonic state (Figure 1). All phases in the biofilm development process were regulated by the cell-to-cell communication system QS. ${ }^{[28]}$ In particular, in MRSA the agr operon has been found fundamental in the modulation of biofilm formation, downregulating genes involved in host colonization including those encoding for the MSCRAMMs, FnBPAB and Spa, and upregulating those encoding for some proteins involved in tissue damage and autolysis. ${ }^{[29]}$

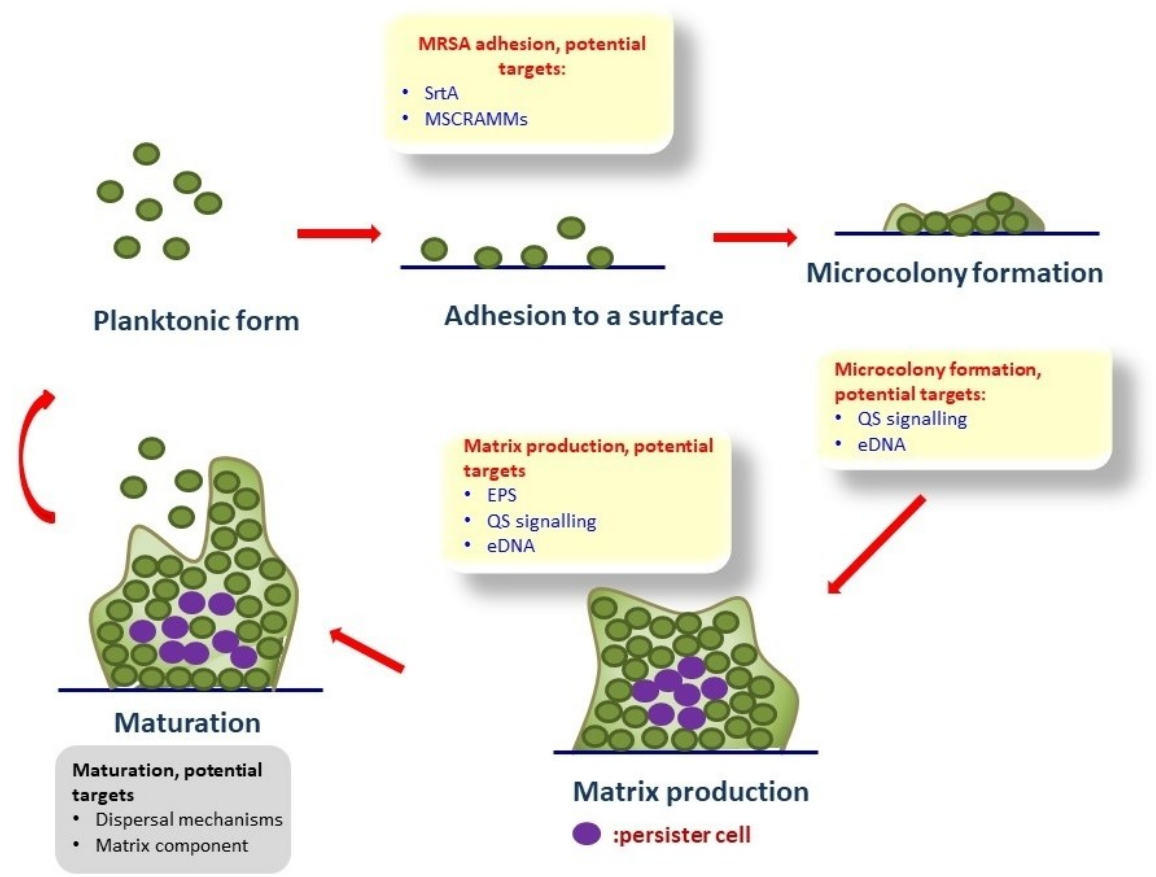

Figure 1. MRSA biofilm development. 


\subsection{Effects of $\beta$-lactam antibiotics on biofilm formation in MRSA}

It was demonstrated that the exposure of bacterial cells to subMIC concentrations of $\beta$-lactam antibiotics induced biofilm formation in many $S$. aureus strains. ${ }^{[30]}$ This has a great impact on the development of resistant strains since antibiotics are widely used as growth promoters in agriculture and then they can contaminate human and animal food in concentrations able to stimulate biofilm formation. ${ }^{[31]}$ The effect of some $\beta$ lactam antibiotics, including methicillin, ampicillin, amoxicillin, and cloxacillin was evaluated, at the sub-MIC concentrations ranging from 0 to $10 \mu \mathrm{g} / \mathrm{mL}$, on the biofilm formation in the MRSA strains 1149, Mu50 and FPR3757 (Figure 2).

All tested antibiotics showed a significant induction of biofilm formation in at least one MRSA strain and, most of them, elicited two different responses toward the biofilm in a concentration-dependent manner: biofilm stimulation at concentrations lower than the MIC values and biofilm inhibition at higher doses. Sub-MICs of methicillin promoted biofilm formation in all three MRSA strains assayed, showing the highest effect at concentrations ranging from 1 to $7 \mu \mathrm{g} / \mathrm{mL}$. Additionally, it was found that biofilm promotion, induced by methicillin exposure, was mainly observed in staphylococcal strains characterized by a low basal level of biofilm production.

Further studies elucidated the mechanism of $\beta$-lactam biofilm induction, which involved an increase in eDNA levels as consequence of upregulation of the autolytic enzyme AltA. The stimulating effect of the cell wall active antibiotics was, in fact, importantly reduced in S. aureus alt mutant strain (KB4051) and in presence of an inhibitor of autolysis such as polyanethole sulfonate. Additionally, the eDNA role in methicillin-induced biofilms was confirmed treating the strains 11490 and FRP3757 with sub-MIC concentrations of the $\beta$-lactam antibiotic in presence and in absence of the human Dnase I, rhDNase. It was observed that rhDNase strongly inhibited methicillin induced biofilm formation.

On the contrary, the antibiotic biofilm induction proved to be independent by the agr quorum-sensing system as previously reported by Subrt et al. ${ }^{[32]}$

This finding suggested as low level of antibiotics may contribute to the growing development of antibiotic resistance and should be avoided in agriculture and farm animals.

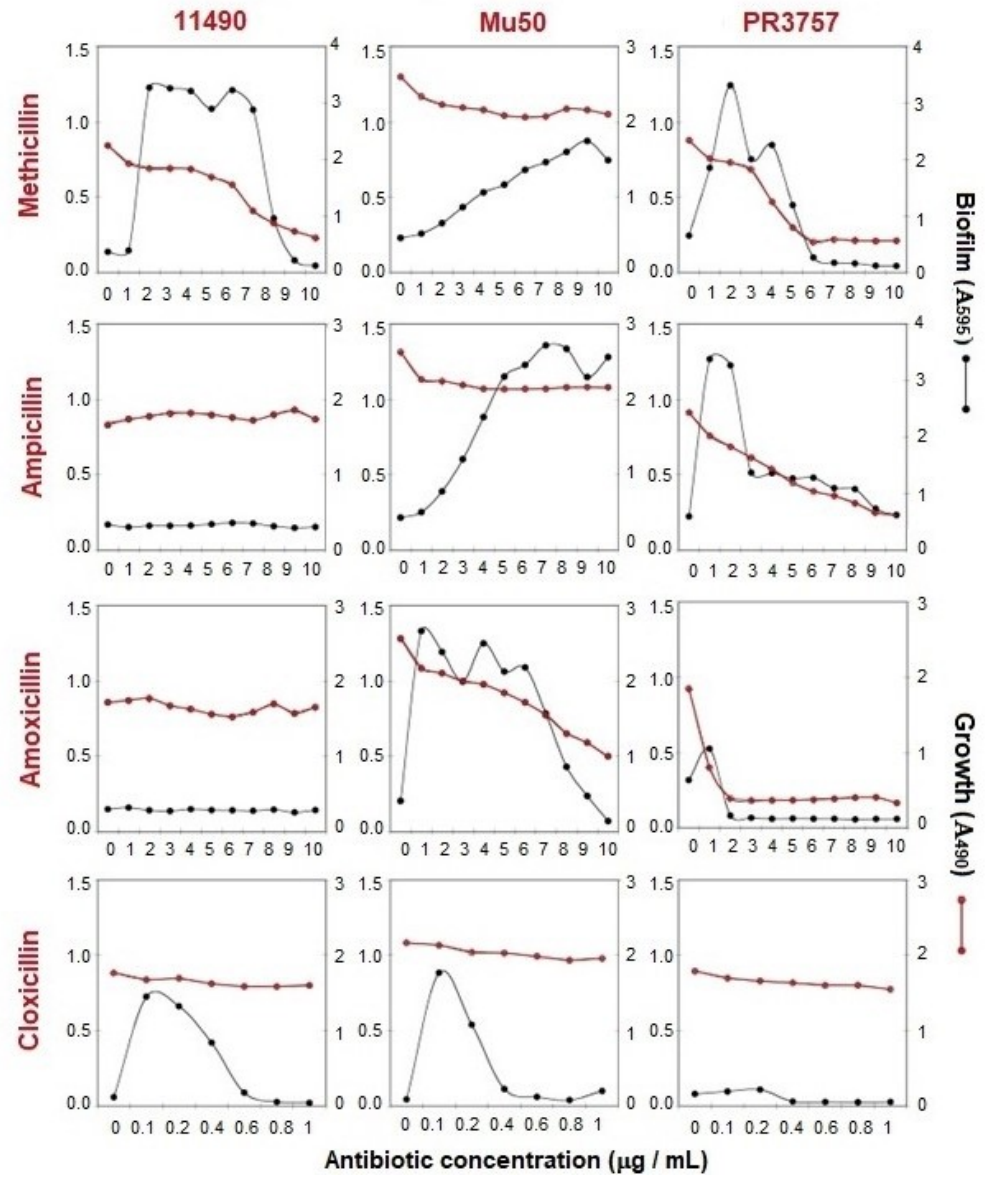

Figure 2. Effects of the $\beta$-lactam antibiotics methicillin, ampicillin, amoxicillin, and cloxacillin at the sub-MIC concentrations ranging from 0 to $10 \mu \mathrm{g} / \mathrm{mL}$ on cell growth and biofilm formation in the MRSA strains 1149, Mu50 and FPR3757. 
<smiles>COc1c(Br)cc(/C=C2\O[C@H](C(Cl)CCNC(=N)N)NC2=O)cc1Br</smiles>

Synoxazolidinone A<smiles>CC(Cl)(Cl)[C@H]1NC(=O)/C(=C/c2ccc(C(F)(F)F)cc2)O1</smiles>

1a<smiles>O=C1NC(C(Cl)(Cl)Cc2ccccc2)O/C1=C\c1ccc(C(F)(F)F)cc1</smiles>

1b<smiles>O=C1NC(C(Cl)(Cl)Cl)O/C1=C\c1ccc(C(F)(F)F)cc1</smiles>

1c

Figure 3. Chemical structures of synoxazolidinone $A$ and its derivative compounds 1 a-c.

\subsection{Inhibitors of MRSA biofilm formation and dispersal agents}

An important contribute to the development of biofilm formation inhibitors against MRSA was given by Melander and collaborators who synthesized several series of 2-aminoimidazole derivatives able to potently inhibit or disperse bacterial biofilms $s^{[33-35]}$ and it was previously discussed. ${ }^{[13]}$ Few new scaffolds were reported in past five years, including oxazolidinones, lactones and quinolines.

\subsubsection{Oxazolidinones}

Edwards et al., on the basis of the antibacterial and anti-biofilm activity described for the natural product synoxazolidinone $A$, $(\text { Figure } 3)^{[36]}$ synthesized a series of 5-benzylidene-4-oxazolidinone derivatives, which were investigated for their ability in inhibiting biofilm-formation in MRSA strains (MRSA ATCC BAA44, 43300,1685 and 1770). ${ }^{[37]}$

Among the new compounds, 4-oxazolidinones 1 a,b (Figure 3) showed the highest potency especially against MRSA ATCC BAA-44, exhibiting BIC $_{50}$ values of 0.78 and $1.2 \mu \mathrm{M}$, respectively. Compound $1 \mathrm{c}$ (Figure 3 ) was slightly less active in the biofilm-formation inhibition assay, eliciting $68 \%$ of inhibition at $5 \mu \mathrm{M}$ vs $89 \%$ and $82 \%$ of $1 \mathrm{a}$ and $1 \mathrm{~b}$ at the same concentration, but it showed a good anti-virulence profile since it did not interfere with the bacterial growth of the tested strain (MIC $>300 \mu \mathrm{M}$ ). With the aim to identify new anti-virulence strategies, the lack of activity toward the vital processes of the bacteria is considered advantageous because is associated to a lower tendency to generate antibiotic-resistance. Concerning the antibacterial activity of $1 \mathrm{a}$ and $\mathbf{1} \mathbf{b}$ against the planktonic form of MRSA, even if they exhibited greater activity compared to $1 \mathrm{c}$, the growth inhibition of planktonic cells observed at the optimal biofilm inhibition concentration was very low, demonstrating a good selectivity towards biofilm form of life.
The new 4-oxazolidinones $1 \mathrm{a}-\mathrm{c}$ also showed a good dispersal activity against MRSA ATCC BAA-44, eliciting, in the case of the most potent derivative $1 \mathrm{a}$ an $\mathrm{IC}_{50}$ value of $4.7 \mu \mathrm{M}$.

SAR studies on these derivatives revealed some important structural features required for the MRSA anti-biofilm activity. The presence of small aliphatic substituents on the aminal carbon of the 4-oxazolidinone scaffold was advantageous for the anti-biofilm properties of this class of compounds, the activity proved inversely proportional to the length of the chain. Additionally, the replacement of the trifluoromethyl group with a hydrogen atom or an electron-donating methoxy substituent was detrimental for the activity indicating the importance of electron-withdrawing substituents in the aromatic ring. Finally, the replacement of chlorine atoms in the dichloromethylene moiety with hydrogen atoms or methyl groups caused a serious drop of the activity.

A great discrepancy in the anti-biofilm activity of derivatives 1a-c among the different MRSA strains tested was observed. These compounds, in fact, showed significantly lower potency against MRSA ATCC 43 300, 1685 and 1770 than MRSA ATCC BAA-44. This so different behaviour deserved further investigation. The lack of studies on the mechanism of action is the main drawback of this class of compounds.

\subsubsection{Lactones}

Valliamai et al. recently reported the anti-biofilm activity of the lactone 5- dodecanolide 2 (Figure 4) in different MRSA strains (ATCC 33591, MRSA 395, MRSA 410 and MRSA44). ${ }^{[38]}$

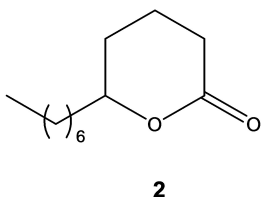

Figure 4. Chemical structure of compound 2. 
<smiles>[R]Oc1c(Br)cc(Br)c2ccc(C)nc12</smiles>

3a-e
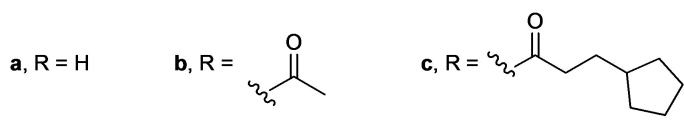<smiles>Cc1ccc(C(=O)C=[Zn])cc1</smiles>

Figure 5. Chemical structures of compounds 3 a-e.

Despite the compound $\mathbf{2}$ proved to be only moderately active as MRSA biofilm inhibitors, eliciting a $\mathrm{BIC}_{50}$ value against the ATCC 33591 of $125 \mu \mathrm{M}$, the in-depth studies conducted on the mechanism of action and on its in vivo efficacy provided the basis for the development of new more potent anti-biofilm agents. The anti-biofilm potential of $\mathbf{2}$ was first confirmed at the concentration of $\mathrm{BIC}_{90}(225 \mu \mathrm{M})$ employing light microscopic and confocal laser scanning microscopic analysis (CLSM), which showed a significant decrease in the surface covered as well as in the thickness of biofilm structure.

SEM analysis showed a marked arrest of MRSA biofilm formation on Titanium surface after treatment with derivative $\mathbf{2}$. Importantly, the compound was able to inhibit biofilm formation also on titanium surface coated with host plasma protein.

Additionally, agarose gel electrophoresis and visual test tube settling assay demonstrated a significant reduction in eDNA synthesis and in the MRSA ability of autoaggregation in a dose dependent manner. It is known, in fact, that eDNA plays a key role in intracellular adhesion and in autoaggregation in MRSA. ${ }^{[30]}$ The effect of compound 2 on MRSA growth and metabolism was evaluated in order to exclude an antibacterial nature of the derivative, and no growth reduction was observed in the growth curve analysis, as well as, no change in MRSA metabolism was found in Almar blue assay. These data highlighted the anti-virulence potential of this compound.

Gene expression analysis was carried out with the aim to understand the molecular mechanism of the antibiofilm activity of compound 2, which was found due to an up regulation of agr gene and to a down regulation of $s a r A, f n b A$ and $f n b B$.

It is reported that agr system hinders the biofilm development interfering with the production of important adhesion proteins and stimulating the expression of many enzymes involved in the disruption of the biofilm matrix, including proteases, nucleases and lipases. ${ }^{[39]}$ The quorum regulator SarA is responsible of the expression of many virulence factors in $S$. aureus, exercising a fundamental role in biofilm formation, bacterial pathogenesis and evasion of the host immune response. Therefore, downregulation of sarA leads to a significant decrease in biofilm formation and in virulence factors. ${ }^{[40]}$ Moreover, FnbA and FnbB are important MSCRAMMs crucial for bacterial adhesion and tissue colonization. ${ }^{[41]}$ Mutant strains with a deletion of the $f n b A$ and $f n b B$ genes did not show the fibronectin-binding proteins FnBPA and FnBPB and were no longer able to adhere to fibronectin or to form biofilm.

The anti-biofilm efficacy of the lactone $\mathbf{2}$ was confirmed in the MRSA in vivo infection model Caenorhabditis elegans. The CLSM micrographs of $C$. elegans treated with compound 2 at $\mathrm{BIC}_{50}$ concentration showed a significant decrease in biofilm formation compared to untreated nematodes.

\subsubsection{Quinolines}

Quinoline derivatives constitute a class of promising compounds for the treatment of MRSA infections. In addition to their significant antibacterial and eradicating activity (see section of Biofilm-eradicating agents) different quinolines were described for their potent dispersal activity. Quinolines 3 a-e (Figure 5) proved to be very potent in dispersing MRSA-2 preformed biofilm showing $\mathrm{EC}_{50}$ values ranging from 2.06 to $2.74 \mu \mathrm{M}$ (Table 1). ${ }^{[42]}$ The potency of the derivatives 3 a-e as dispersal agents was evaluated also in terms of $E C_{90}$ values and all compounds showed $\mathrm{EC}_{90}$ values against established MRSA-2 biofilms lower than $30 \mu \mathrm{M}$. In particular, compound $3 \mathrm{c}$, substituted at the 8-position of the quinoline scaffold with a 3cyclopentylpropanoate and $\mathbf{3} \mathbf{d}$ bearing at the same position a 4-methylbenzoate moiety, exhibited the highest potency with $\mathrm{EC}_{90}$ of 16.6 and $17.4 \mu \mathrm{M}$, respectively. Compounds 3 a-e showed potent antibacterial activity also against the planktonic form of S. aureus ATCC 29213 eliciting MIC values in the range 0.39-1.56 $\mu \mathrm{M}$ (Table 1) but no data were reported on their activity on the free form of MRSA.

\begin{tabular}{|c|c|c|c|}
\hline Compound & $\begin{array}{l}\text { S. aureus ATCC } \\
29213 \\
\text { MIC }[\mu \mathrm{M}]\end{array}$ & $\begin{array}{l}\text { MRSA-2 } \\
\text { biofilm dispersion } \\
\mathrm{EC}_{50}[\mu \mathrm{M}]\end{array}$ & $\begin{array}{l}\text { MRSA-2 } \\
\text { biofilm dispersion } \\
\mathrm{EC}_{90}[\mu \mathrm{M}]\end{array}$ \\
\hline $3 a$ & 0.39 & 2.60 & 22.9 \\
\hline $3 b$ & $0.39-0.78$ & 2.55 & 22.9 \\
\hline $3 c$ & $0.78-1.56$ & 2.09 & 16.6 \\
\hline $3 d$ & 1.56 & 2.06 & 17.4 \\
\hline $3 e$ & 0.39 & 2.74 & 24.0 \\
\hline
\end{tabular}




\subsubsection{Thiazole derivatives}

Thiazole ring is widely recognized as scaffold of great value for obtaining molecules endowed with potent antibacterial and anti-biofilm properties. ${ }^{[15,43]}$ Recently, the 5-acetyl-4-methyl-2-(3pyridyl) thiazole 4 (Figure 6) was found able to interfere with the QS system as well as with the production of virulence factors including biofilm formation. ${ }^{[44]}$ The antivirulence effects were evaluated on the clinical isolates MRSA-C18 and MRSA-C91, which are known for their multidrug-resistance and their strong biofilm forming capacity. Thiazole 4 was more active than vancomycin and teichoplanin in inhibiting MRSA growth in the planktonic form, additionally, it proved to significantly reduce biofilm formation at subinhibitory concentrations. The compound acted in the first stage of the MRSA biofilm formation showing no activity in preformed biofilm of the same strains. With the aim to investigate the anti-virulence mechanism of action of thiazole 4, the effect on the MRSA production of haemolysin and protease was evaluated, and a reduced activity in both enzymes was observed after treatment with the thiazole derivative. The results are in agreement with an anti-QS mechanism targeting the Agr QS system.

\subsubsection{Coumarin derivatives}

During a study aiming to identify novel small molecules with antibacterial activity against MRSA, Qu et al. synthesized and evaluated for their antimicrobial properties, new 667 derivatives bearing to 26 different classes of compounds, including coumarin, hydroquinoline, diludine, hydropyran, and acridine derivatives. ${ }^{[45]}$ Among these compounds 3,3'-(3,4-dichlorobenzylidene)-bis-(4-hydroxycoumarin) 5 showed potent inhibitory effects on the growth and the biofilm formation of the MRSA strains ATCC 70699, USA 300 and XJ 75302. Compound 5 (Figure 7) exhibited a marked selectivity against MRSA, showing

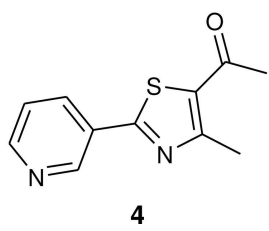

Figure 6. Chemical structure of the thiazole derivative 4 .

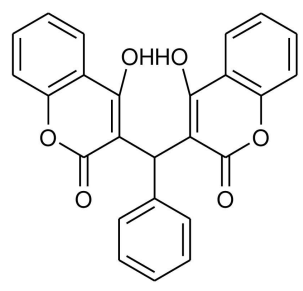

5 no activity against Gram-negative pathogens such as $E$. coli, $K$. pneumoniae, A. baumannii, Salmonella typhimurium, and $P$. aeruginosa. In vitro experiments showed MRSA growth inhibition at concentration of 4 or $8 \mu \mathrm{g} / \mathrm{ml}$. Importantly, the therapeutic effect against the MRSA infections was also evaluated in vivo in mice infected with MRSA USA 300, and coumarin derivative 5 , intraperitoneally administered at concentrations of 2.5 and $5 \mathrm{mg} / \mathrm{kg}$, proved to be able to improve the survival rate to 56 and $67 \%$, respectively.

Noteworthy, the antibiofilm activity against the MRSA strains of compound $\mathbf{5}$ was assayed in vivo for evaluating the effect on MRSA adhesion to a catheter surface inserted in the rat bladder. These results are particular relevant since one of the major cause of the absence of antibiofilm agents in clinic was due to the lack of in vivo studies. Compound 5 administered at doses of 5 and $10 \mathrm{mg} / \mathrm{kg}$ inhibited MRSA USA 300 adhesion and biofilm formation on the surface of the catheter. Additionally, it was also able to inhibit the diffusion of the pathogen from the catheter to the liver, lung, kidney and spleen.

Quantitative real-time polymerase chain reaction (PCR) elucidated a mechanism of action involving the inhibition of the expression levels of the genes srtA, altE, aap, icaA and arc gene cluster transcription. In particular compound 5 proved to be able to interfere with the arginine catabolic pathway by competitively binding to the arginine repressor ArgR.

The toxicity of the coumarin derivative 5 was evaluated both in vitro, against human umbilical vein endothelial cells (HUVECs) and cells from human embryonic myocardial tissue (CC-HHM-2), and in vivo, in mice and rats after oral administration. Results highlighted a low toxicity of the compound, which showed a therapeutic index in mouse of 37.56. Additionally, treatment with $2 \times, 4 \times$ and $8 \times$ MIC 5 did not induce resistance in treated bacterial strains. On the basis of the obtained results, compound $\mathbf{5}$ can be considered an ideal lead compound for development of new therapeutic approaches to fight MRSA infections.

\subsection{Biofilm-eradicating agents}

Biofilm eradicating agents, differently from biofilm inhibitors and biofilm dispersal agents, act killing persister cells within the biofilm. This distinct mechanism of action confers them the potential to be employed as standalone antibiofilm therapy. Antimicrobial peptides (AMP), which cause bacterial cell lysis through the crushing of the bacterial membrane, are the most well known biofilm eradicating agents. ${ }^{[46,47]}$ The main obstacle for their development in clinical use is the difficulty to obtain AMP which are able to target selectively bacterial cell membrane. Therefore, it should be useful in this field to identify new agents able to kill dormant cells through alternative mechanisms of action, for which a higher selectivity is feasible.

Figure 7. Chemical structure of the coumarin derivative $\mathbf{5}$. 


\subsubsection{Phenazines}

Diverse classes of phenazines were described as MRSA biofilmeradicating agents, which are able, unlike the inhibitors of biofilm formation and the dispersal agents, to kill persister cells. Since conventional antibiotics, affecting life processes of the bacterium, are not efficacious against the non-replicating dormant cells, these are often the main cause of the resistance of the biofilm-associated infections.

On the basis of the potent antibacterial activity observed for the marine phenazine antibiotic 6 (Figure 8) Garrison and coworkers synthesized a series of halogenated phenazines (HPs) with the aim to enhance their antimicrobial potency and in order to obtain compounds which were also capable of inhibiting persistent cells. ${ }^{[48-50]}$ The influence of the substitutions at the positions 2-, 4-, 7-, and 8- of the phenazine scaffold, on both antibacterial and biofilm eradicating activity, was widely studied providing pivotal information on the structural features required for the activity. ${ }^{[4]}$ Among the tested compounds derivative (2-bromo-7,8-dichloro-4-iodo-1-hydroxyphenazine) 7 (Figure 8) showed, in the Calgary biofilm device (CDB) assay, ${ }_{1}^{[51]}$ the highest activity against MRSA biofilms (MRSA-2, MRSA BAA1707, MRSA BAA-44) eliciting minimum biofilm eradication concentration (MBEC) values ranging from 6.25 to $9.38 \mu \mathrm{M}$ (Table 2). The viable biofilm cell count at the MBEC value highlighted the almost total eradication of the persister cells within the biofilm.

Since the antibiotics normally used in the treatment of MRSA infections, including vancomycin, daptomycin and linezolid, were ineffective against MRSA biofilms and persister cells at concentration higher than $2000 \mu \mathrm{M}$, the results obtained for compound 7 are very encouraging. Additionally, compound 7 was compared to known biofilm- or persister-eradicating agents such as the AMP mimic membrane lysing agent QAC-10 (quaternary ammonium cation-10), the membrane-active ionophore CCCP (carbonyl cyanide $m$-chlorophenyl hydrazine), the antioxidant NAC (N-acetylcysteine), and persister cells eradicator

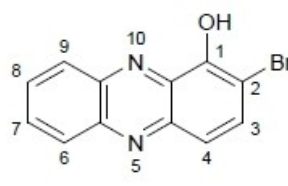

6

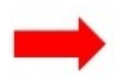<smiles>[R]c1cc2nc3c(O)c([Y])cc([X])c3nc2c([R])c1[R]</smiles>

7, $\mathrm{R}^{1}=\mathrm{R}^{2}=\mathrm{Cl}, \mathrm{R}^{3}=\mathrm{H}, \mathrm{Y}=\mathrm{Br}, \mathrm{X}=\mathrm{I}$ 8, $\mathrm{R}^{1}=\mathrm{R}^{2}=\mathrm{H}, \mathrm{R}^{3}=\mathrm{CH}_{3}, \mathrm{X}=\mathrm{Y}=\mathrm{Br}$ 9, $\mathrm{R}^{1}=\mathrm{R}^{2}=\mathrm{H}, \mathrm{R}^{3}=\mathrm{C}_{2} \mathrm{H}_{5}, \mathrm{X}=\mathrm{Y}=\mathrm{Br}$

Figure 8. Chemical structures of compounds 6-9.

pyrazinamide. All the known anti-biofilm compounds proved to be 12 to 200 -fold less active in eradicating MRSA biofilms than the HP 7. With the aim to investigate a possible membranelysing mechanism of action the hemolysis activity against human red blood cells was evaluated at the screening concentration of $200 \mu \mathrm{M}$ and, as observed generally for phenazine analogs, also in this case no significant hemolysis was found $(<3 \%)$. These results suggested a different mechanism of action with respect to the prevalent class of biofilmeradicating agents described to date, which is constituted by the AMPs. ${ }^{[47,52]}$ A non-hemolytic mechanism of action may be beneficial to achieve lower human toxicity, which is one of the main impediments to obtaining therapeutically valid AMPs that should specifically target bacterial membranes over mammalian cell membranes. ${ }^{[53]}$ The low toxicity of the phenazine analogs synthesized, was also confirmed in a lactate dehydrogenase (LDH) release assay against HeLa cells highlighting the promising therapeutic profile of this class of compounds to be developed into a new class of antimicrobial agents to treat serious MRSA infections.

Preliminary mechanistic investigations elucidated a metal (II)-dependent eradicating mechanism of action. The co-treatment of phenazine 7 , at the MIC concentration, with $200 \mu \mathrm{M}$ of copper(II), iron(II) and magnesium(II) resulted in a significant reduction in antibacterial activity, up to 48 times in the case of copper(II).

Based on the interesting results, new HP were synthesized in order to obtain more potent biofilm-eradicating agents against MRSA. ${ }^{[5]}$

The Wohl-Aue reaction was employed to lead a small library of HPs bearing different substituents at the 6-, 7-, 8- and 9positions. Among the new compounds 2,4-dibromo-HP analogs 8 and 9 (Figure 8) showed the highest antibacterial activity against both the planktonic and the biofilm form of MRSA BAA1707. HP 8 and 9 proved to be equipotent against the planktonic form eliciting a MBC value of $6.25 \mu \mathrm{M}$ (Table 2). Additionally, they showed potent biofilm-eradicating activity with MBEC values of 6.25 and $4.69 \mu \mathrm{M}$, respectively. At the MIC concentration, the new HP analogs 8 and 9 demonstrated an important reduction (99.9\%) in viable MRSA BAA-1707 biofilm cells.

Similarly to HP 7, compounds 8 and 9 showed a metal (II) chelating mechanism of action and a lack of red blood cell hemolysis and HeLa cytotoxicity. Among biofilm-eradicating agents effective against MRSA, HP analogs showed interesting features to be developed into innovative treatments of chronic biofilm-associated MRSA infections. 1-Hydroxyl group and 2bromine atom on the phenazine scaffold were recognized key structural features for the antimicrobial activity of this class of

\begin{tabular}{|c|c|c|c|c|c|c|c|c|c|}
\hline \multirow[b]{2}{*}{ Compound } & \multicolumn{3}{|l|}{ MRSA-2 } & \multicolumn{3}{|c|}{ MRSA BAA 17-07 } & \multicolumn{3}{|c|}{ MRSA BAA-44 } \\
\hline & MIC & MBC & MBEC & MIC & $\mathrm{MBC}$ & MBEC & MIC & $\mathrm{MBC}$ & MBEC \\
\hline 8 & 0.30 & - & - & 0.30 & 6.25 & 6.25 & 0.39 & - & - \\
\hline 9 & 0.39 & - & - & 0.10 & 6.25 & 4.69 & 0.59 & - & - \\
\hline
\end{tabular}


compounds. The presence of an additional bromine atom at 4position as well as a methyl or ethyl group at 6-position was advantageous for both antibacterial and biofilm eradicating activity. Furthermore, two chlorine atoms at 7- and 8- positions proved to be relevant for the eradication potency against MRSA-2, MRSA BAA-1707 and MRSA BAA-44 strains. On the contrary, the replacement of the two chlorine atoms at the same positions with two bromine atoms as well as removing the halogen from position 4 led to a significant loss of activity.

\subsubsection{Quinolines}

With the aim to identify novel potent antibiofilm compounds to counteract MRSA infections a series of halogenated quinolines (HQs), structurally related to HPs, were investigated in vitro in antibacterial and biofilm eradication assays. ${ }^{[45,55]}$ Among the new quinolines, several derivatives showed potent antibacterial activity, with MICs in some cases lower than $1 \mu \mathrm{M}$, and biofilm dispersal action against methicillin-resistant $S$. aureus clinical isolate MRSA-2, with $\mathrm{EC}_{50}$ in the low micromolar range (See the section 4). Conversely, regarding MRSA biofilm eradication, the replacement of the HP scaffold with the HQ nucleus was detrimental for the activity. HQ analogs were inactive or only weakly active. The first HQ that showed a weak biofilm eradicating activity with a metal(II)-dependent mechanism against MRSA (MBEC $=250 \mu \mathrm{M})$ was the quinoline 10 (Figure 9). ${ }^{[55]}$

Basak et al. during a study aimed to investigate structural modifications at the 2-position of the HQ scaffold, which was recognized crucial for the antibacterial activity, identified compound 11 (Figure 9), which was slightly more active than 10 but significantly less active than the HP analogues, showing a MBEC value against MRSA-2 of $125 \mu \mathrm{M}$.

Abouelhassan et al. described the potentiating effect of the plant derived phytochemical gallic acid 12 (Figure 9) on the antibacterial and eradicating activity of the $\mathrm{HQ} 10^{[56]}$ The combination therapy (HQ 10 at MIC concentration $+121 \mathrm{mM}$ ) was 11800 -fold more potent against S. aureus 29213 with a MIC value of $0.05 \mathrm{nM}$, and, interestingly, was 4-fold more effective in the biofilm-eradication assays, showing a MBEC value of $62.5 \mu \mathrm{M}$ vs $250 \mu \mathrm{M}$ of HQ 10 used alone.<smiles>[R]c1ccc2c(Br)cc(Br)c(O)c2n1</smiles><smiles>O=C(O)c1cc(O)c(O)c(O)c1</smiles><smiles></smiles>

Figure 9. Chemical structures of compounds 10-12.

\subsubsection{Quinones}

Quinone derivatives are a class of synthetic and natural compounds endowed with different pharmacological activities, including antiviral, antifungal, antibacterial and anti-biofilm properties. ${ }^{[57]}$ Structurally they are characterized by a common pattern constituted by an ortho or a para substituted dione conjugated to an aromatic cycle such as in the benzoquinones, or to polycyclic aromatic system, such as in anthraquinones, naphtoquinones and anthracyclinones. Recently, three furanoquinones 13, 14 a and 14b (Figure 10) were described for their interesting activity against MRSA. ${ }^{[8,59]}$

The naphtho[1,2-b]furan-4,5-dione 13, tested against MRSA ATCC 33591 and the two MRSA clinical isolates KM-1 and KM-2, proved to be significantly more potent than oxacillin (MIC $=160$ - $630 \mu \mathrm{M}$ ) used as reference compound, eliciting MIC values in the range 4.9-9.8 $\mu \mathrm{M}$. (Table 3). ${ }^{[58]}$ Studies on MRSA morphology carried out through a transmission electron microscopy (TEM) before and after treatment with 13 highlighted the ability of the compound to cause a bacterial surface damage. The presence of depressions on the cell surface suggested the loss of intracellular material due to an osmotic alteration of the bacterial membrane. A proteomic assay, employed to deepen the mechanism of action of compound 13, suggested strong interferences with crucial bacterial metabolic pathways, including translocase elongation factor $G(E F-G)$, phosphoenolpyruvate carboxykinase (PEPCK), citrate synthase and arginine deiminase. In particular, the profiling assay of MRSA proteins revealed that furanoquinone potently inhibited staphylococcal EF-G, which plays a key role in bacterial protein synthesis, catalysing the translocation of transfer RNA (tRNA) and messenger RNA ( $m R N A$ ) through the ribosome. The consequent inhibition of protein synthesis in MRSA led to bacterial death.<smiles>O=C1C(=O)c2ccoc2-c2ccccc21</smiles>

13<smiles>[R]N=C1C(=O)c2ccccc2-c2occc21</smiles>

14a, $\mathrm{R}=\mathrm{OH}$

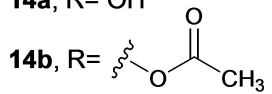

Figure 10. Chemical structures of compounds 13 and $14 \mathrm{a}, \mathrm{b}$.

\begin{tabular}{|c|c|c|c|c|c|c|c|c|}
\hline \multirow[t]{2}{*}{ Compound } & \multicolumn{2}{|c|}{ MRSA KM-1 } & \multicolumn{2}{|c|}{$\begin{array}{l}\text { MRSA KM- } \\
2\end{array}$} & \multicolumn{2}{|c|}{ MRSA KM-5 } & \multicolumn{2}{|c|}{$\begin{array}{l}\text { MRSA ATCC } \\
33591\end{array}$} \\
\hline & MIC & MBC & MIC & MBC & MIC & MBC & MIC & $\mathrm{MBC}$ \\
\hline 13 & 4.9 & $\begin{array}{l}4.9- \\
9.8\end{array}$ & $\begin{array}{l}4.9- \\
9.8\end{array}$ & $\begin{array}{l}4.9- \\
19\end{array}$ & - & - & $\begin{array}{l}4.9- \\
9.8\end{array}$ & $\begin{array}{l}9.8- \\
39\end{array}$ \\
\hline $14 a$ & $\begin{array}{l}45.5- \\
91.5\end{array}$ & $\begin{array}{l}91.5- \\
183.0\end{array}$ & - & - & $\begin{array}{l}11.7- \\
91.5\end{array}$ & $\begin{array}{l}91.5- \\
731.7\end{array}$ & $\begin{array}{l}45.5- \\
91.5\end{array}$ & 91.5 \\
\hline $14 \mathrm{~b}$ & 76.4 & $\begin{array}{l}76.4- \\
152.8\end{array}$ & - & - & $\begin{array}{l}9.4- \\
76.4\end{array}$ & $\begin{array}{l}76.4- \\
152.8\end{array}$ & $\begin{array}{l}9.4- \\
38.0\end{array}$ & 76.4 \\
\hline
\end{tabular}


An important downregulation in bacterial PEPCK expression was found as a consequence of the exposure to derivative 13. Being PEPCK an enzyme involved in the gluconeogenesis, its inhibition led to the bacterial death because of the absence of glucose, which is fundamental for the microbial growth. Derivative 13 proved to be active also in inhibiting citrate synthase, which catalyzes the last steps of Krebs cycle and finally, it interfered with the arginine metabolism, hindering the enzyme arginine deiminase which is well known as important virulence factor responsible of the MRSA invasion and growth in host cells.

Compound 13 was found able to reduce biofilm thickness from 24 to $16 \mu \mathrm{m}$ and to kill bacterial cells inside the immune cells THP-1 (human myelomonocytic cell line), showing low toxicity toward macrophages at the biocidal dose.

Subsequently, two furanoquinone derivatives containing imine moiety, $14 \mathrm{a}$ and $\mathbf{1 4} \mathrm{b}$, were found able to eradicate MRSA biofilm causing, at concentrations ranging from 391 to $469 \mu \mathrm{M}$, a 1000-fold reduction of the bacterial cells inside the biofilm with a biofilm thickness reduction from 30 to $17.2 \mu \mathrm{m}$ for the most active compound $14 \mathrm{a} .{ }^{[59]}$ Considering the high morbidity and mortality due to colonization of cutaneous wounds by MRSA biofilms the in vivo efficacy of the two compounds in treating skin infection was also assayed in mice subcutaneously inoculated with MRSA. Topical application of the two compounds led to a significant reduction of MRSA-infected abscess after two days treatment, causing only a very slight skin irritation on intact mouse skin. Compounds $14 \mathrm{a}$ and $14 \mathrm{~b}$ proved to be active also against the planktonic form of MRSA ATCC 33591 (Table 3) eliciting a bactericidal effect as their MBC values are no higher than $4 \mathrm{xMIC}$ values. Even if structurally very similar to compound 13 , for furanoquinones $14 \mathrm{a}$ and $14 \mathrm{~b}$ no bacterial membrane damage was observed by scanning electron microscopy (SEM). In order to clarify the mechanism of action, the total amount of DNA, RNA and proteins were quantified in MRSA cells treated with the furanoquinones $14 \mathrm{a}$ and $14 \mathrm{~b}$ and a significant decrease in DNA content was observed. The inhibitory activity of the compounds against DNA polymerase, topoisomerase I and gyrase was evaluated in polymerase chain reaction analysis (PCR) and in a wrapping assay. Derivatives $14 a$ and $\mathbf{1 4} b$, at concentrations ranging from 0.3 to $9 \mu \mathrm{M}$, were inactive against topoisomerase I whereas they interfered with DNA polymerase and gyrase.

\subsection{Aryl-alkyl-lysines}

Another class of compounds described for its promising antibacterial activity against the persister cells is constituted by the membrane active aryl-alkyl-lysines of type 15 (Figure 11). ${ }^{[60]}$

All the four compounds 15 a-d showed antibacterial good activity against the planktonic form of three MRSA strains, including ATCC 33591, R3889 and R3890, with MIC value ranging from 4.1 to $25.5 \mu \mathrm{M}$ (Table 4). Importantly, they elicited no propensity to induce resistance in Gram-positive strains, since they maintained unchanged the MIC value toward $S$. aureus MTCC 737 after 20 treatments at the highest concen-<smiles>[R]N(C[Al])C(=O)C(N)CCCCN</smiles>

$$
\begin{array}{ll}
\text { 15a, } & R=\mathrm{C}_{8} \mathrm{H}_{17}, A r=\mathrm{C}_{10} \mathrm{H}_{7} \\
\text { 15b, } & \mathrm{R}=\mathrm{C}_{10} \mathrm{H}_{21}, \mathrm{Ar}=\mathrm{C}_{10} \mathrm{H}_{7} \\
\text { 15c, } & \mathrm{R}=\mathrm{C}_{10} \mathrm{H}_{21}, \mathrm{Ar}=\mathrm{C}_{6} \mathrm{H}_{5} \\
\text { 15d, } & \mathrm{R}=\mathrm{C}_{12} \mathrm{H}_{25}, \mathrm{Ar}=\mathrm{C}_{6} \mathrm{H}_{5}
\end{array}
$$

\begin{tabular}{|c|c|c|c|c|}
\hline \multirow[t]{3}{*}{ Compound } & \multicolumn{4}{|c|}{ Minimum Inhibitory Concentration $[\mu \mathrm{M}]$} \\
\hline & S. aureus MTCC & MRSA ATCC & MRSA & MRSA \\
\hline & 737 & 33591 & R3889 & R3890 \\
\hline $15 \mathrm{a}$ & $10.8 \pm 1.7$ & $8.8 \pm 2.6$ & $10.8 \pm 1.7$ & $7.9 \pm 1.0$ \\
\hline $15 \mathrm{~b}$ & $5.7 \pm 0.5$ & $4.1 \pm 0.1$ & $4.4 \pm 0.3$ & $4.8 \pm 0.3$ \\
\hline $15 c$ & $10.9 \pm 0.1$ & $25.5 \pm 0.2$ & $11.3 \pm 1.4$ & $10.2 \pm 0.4$ \\
\hline $15 d$ & $5.5 \pm 1.1$ & $5.1 \pm 0.6$ & $4.5 \pm 0.3$ & \pm 1.1 \\
\hline
\end{tabular}

Figure 11. Chemical structures of compounds $15 \mathrm{a}-\mathrm{d}$.

tration of half of MIC, whereas the MIC of norfloxacin, used as reference compound, increased by 800 fold. Derivative $15 \mathrm{~b}$ was chosen as representative compound of the series for further studies in order to evaluate the anti-biofilm properties and the mechanism of action of this class of compounds. Naphthalene derivative $15 \mathrm{~b}$ was able to remove the $S$. aureus persister cells completely at the concentration of $5 \times \mathrm{MIC}$, which is a very interesting result considering that ampicillin was ineffective against persister cells at concentrations higher than 500xMIC. This effect on the dormant cells seemed to be due to the membrane active properties of the compound, which proved to be able of strongly depolarizing the membrane within the first minute of exposure.

At $10 x$ MIC $15 \mathrm{~b}$ significantly reduced pre-formed MRSA (ATCC 33591) biofilm leading to a biofilm thickness reduction from 23 to $2 \mu \mathrm{m}$. Since skin infections represent one of the most relevant problems caused by MRSA in hospital, efficacy of $15 \mathrm{~b}$ was confirmed in an in vivo mice model of skin infection. The results indicated higher potency in treating infections compared to fusidic acid used as reference drug.

\subsection{Antibiotics}

The susceptibility of the planktonic and the biofilm forms of MRSA to conventional antibiotics was investigated with the aim to identify an efficacious combination therapy to treat chronic biofilm-associated infections. Vancomycin is a glycopeptide antibiotic extensively used as first-line treatment for serious MRSA infections, including endocarditis, meningitis, bacteremia and osteomyelitis. Unfortunately, its extensive use together with the need to use increasing dosages in an attempt to 
penetrate the MRSA biofilm, over time, have led to a significant increase in the MIC of this antibiotic. ${ }^{[61]}$

Chopra et al. studied the anti-biofilm properties of clindamycin, vancomycin and minocycline (Figure 12) against two different strains of MRSA: ATCC 33591 and ATCC 43 300..$^{\text {[62] }}$

The choice of the two strains was made in order to evaluate the influence of the presence of the intercellular adhesion (ica)locus on the bacterial susceptibility to the antibiotics, MRSA ATCC 33591 is, in fact, an ica-locus positive strain whereas ATCC 43300 is an ica-locus negative strain. Both are well-known biofilm producer strains but the composition of the biofilm matrix is very different.

Ica-locus is involved in the production of the polysaccharide intercellular adhesin (PIA), which is composed of linear glucosaminoglycans and plays a key role in the intercellular adhesion during the biofilm formation. ${ }^{[63]}$ Therefore, the biofilm matrix of the ica-locus positive strain MRSA ATCC 33591 was mainly made of PIA. Instead, the main component of the biofilm matrix in ica-locus negative strain ATCC 43300 is eDNA. The biofilm eradication activity of vancomycin and minocycline was evaluated in both strains in order to compare their effectiveness.

All the three antibiotics proved to be active against the tested MRSA strains in planktonic growth with similar potency against the two strains (Table 5), substantial differences were indeed observed regarding the anti-biofilm effect against the two strains. In particular, vancomycin showed a good biofilmeradicating activity against the ica-locus negative strain on mature biofilm with MIC and MBC values of 11-22 $\mu \mathrm{M}$, respectively. On the contrary, the same antibiotic showed no effect in eradicating ica-positive MRSA biofilm eliciting MBC value higher than $700 \mu \mathrm{M}$. These so different results were probably due to the different composition of the biofilm matrix in the two strains: the presence of PIA in the matrix confers a greater density to the biofilm structure, which becomes difficult the penetration of the vancomycin.

Differently, the tetracycline minocycline proved to be quite active in eradicating both ica-negative and ica-positive MRSA mature biofilm with $M B C$ values of 4.3 and $34 \mu \mathrm{M}$, respectively.

Moreover, only minocycline showed also a significant inhibition of biofilm formation in the two strains. Probably, the effect against ica-negative biofilm was due to the suppression of Alt (major autolysin), which is involved in the initial bacterial adhesion to the surface and in the lysis of bacterial cells that determines the eDNA release in the biofilm matrix. ${ }^{[64]}$ The results highlighted the correlation between the anti-biofilm efficacy of vancomycin and minocyclin with the biochemical composition of MRSA biofilm.

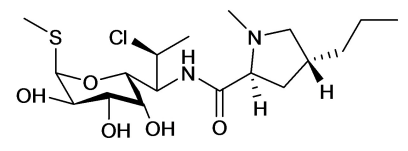

Clindamycin<smiles>CN(C)c1ccc(O)c2c1C[C@H]1C[C@H]3[C@H](N(C)C)C(=O)C(=C(N)O)C(=O)[C@@]3(O)C(=O)C1=C2O</smiles>

Minocyclin

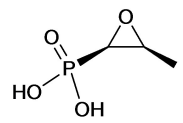

Fosfomycin

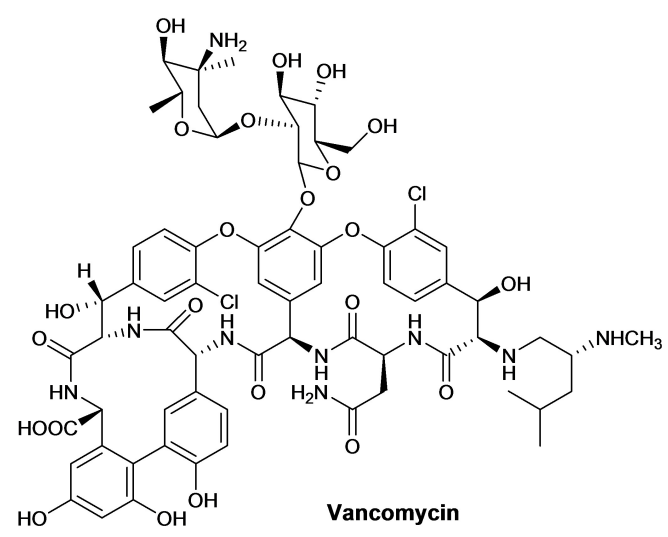

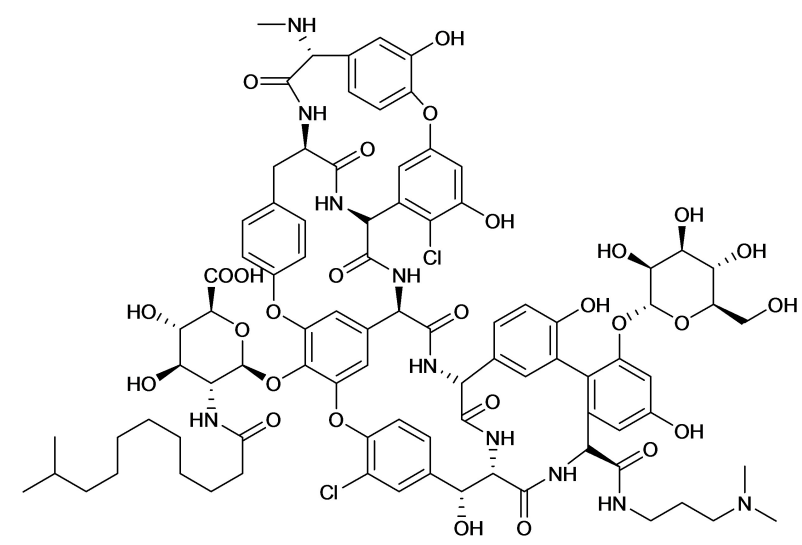

Dalbavancin

Figure 12. Chemical structure of clindamycin, vancomycin, minocycline, fosfomycin and dalbavacin. 
Table 5. Antibiotic susceptibility of three antibiotics against MRSA biofilms in different phases of biofilm formation.

\begin{tabular}{|c|c|c|c|c|}
\hline & & $\begin{array}{l}\text { Clindamycin } \\
{[\mu \mathrm{M}]}\end{array}$ & $\begin{array}{l}\text { Vancomycin } \\
{[\mu \mathrm{M}]}\end{array}$ & $\begin{array}{l}\text { Minocyclin } \\
{[\mu \mathrm{M}]}\end{array}$ \\
\hline $\begin{array}{l}\text { Mode of } \\
\text { growth }\end{array}$ & $\begin{array}{l}\text { Initial bac- } \\
\text { terial den- } \\
\text { sity } \\
{\left[\text { CFU mL }{ }^{-1} \text { ] }\right.}\end{array}$ & MIC $\quad$ MBC & MIC $\quad \mathrm{MBC}$ & MIC MBC \\
\hline
\end{tabular}

ica-nega-

tive MRSA

tonic

$\begin{array}{llllllll}\text { Stationary } 1.1 \times 10^{7} & - & > & & 2409 & - & 11 & -\end{array}$

planktonic

Mature

biofilm

$\begin{array}{lllllll}1.3 \times 10^{-7} & >2409 & >2409 & 11 & 22 & 1 & 4.3\end{array}$

ica-posi-

tive MRSA

Log plank- $3.4 \times 10^{5} \quad 301 \quad 602$

tonic

Stationary $3.5 \times 10^{8}$

planktonic

Mature

biofilm
Considering the genetic heterogeneity of the resistant bacterial cells inside the biofilm and the growing loss of activity of vancomycin toward MRSA infections, the effectiveness of combinations of vancomycin with other antibiotics in inhibiting MRSA biofilm were evaluated.

Shi et al. reported an in vivo study on the synergistic bactericidal effect of the association vancomycin-fosfomycin on chronic biofilm-associated MRSA infection. ${ }^{[65]}$ The in vitro efficacy of this antibiotics combination against planktonic and biofilm forms of $S$. aureus and different MRSA strains were previously described. ${ }^{[66,67]}$

Vancomycin and fosfomycin elicited, when used alone, MIC values against MRSA KZ306 and ATCC43300 of 1.3 and $14.5 \mu \mathrm{M}$, respectively, but bacterial regrowth was observed after $24 \mathrm{~h}$. Lasting and long-term bactericidal effect on MRSA was recorded in presence of higher concentrations, approximately 8-fold the MIC value. Combination therapy of the two antibiotics provided better results, showing a complete antibacterial effectiveness at significant lower concentrations (MIC vancomycin $+1 / 2$ MIC fosfomycin).

The synergistic antibacterial activity of the two antibiotics was also evaluated against the biofilm. It is known that the association of antibiotics with different mechanisms of action can give good results in biofilm eradication for the theory of the mutant selection window. ${ }^{[68]}$ For this theory, in fact, the simultaneous use of antibiotics with different bactericidal effect, prevent mutant selection and decrease the side effects. In the case of the association vancomycin-fosfomycin, for example, a significant reduction of the renal toxicity of vancomycin was observed, thus providing an important advantage for antibacterial therapy in patients with renal failure.

Furthermore, the synergistic effect of the two antibiotics was evaluated in vivo in a carboxymethyl cellulose (CMC)-pouch biofilm model in rats. The CMC pouch was made through an injection, in the animals, of a mixture of $5 \mathrm{~mL}$ of $\mathrm{CMC}$ and $5 \mathrm{~mL}$ of $1 \times 10^{7} \mathrm{CFU} / \mathrm{mL}$ of MRSA KZ306 or ATCC43300.

Nine days after the inoculation of the bacteria, which is the time required to obtain a mature biofilm, vancomycin and fosfomycin were administered intraperitoneally, alone or in combination, at the dosage of $100 \mathrm{mg} / \mathrm{Kg}$ and $200 \mathrm{mg} / \mathrm{Kg}$, respectively.

For both strains the combination therapy proved to be significantly more potent than the mono-administration in eradicating mature biofilm. The in vivo model was employed not only to evaluate the ability of the antibiotics in killing bacterial inside the biofilm, but also to study the structural modification and the inflammatory response of the biofilm. The histological analysis of MRSA biofilm tissue showed a marked loss of the biofilm structure and a notable reduction of the necrosis process. After 9 days of treatment with the combination therapy, the animals elicited a remarkable decrease in white blood cells, in C-reactive protein in blood samples and in exudate colonies. Results confirmed in vivo the synergic bactericidal activity of vancomycin and fosfomycin in the treatment of chronic MRSA infections.

Recently, the in vitro efficacy of the novel lipoglycopeptide dalbavancin against MRSA-biofilm associated infections was investigated. ${ }^{[69]}$ Compared to vancomycin, dalbavancin proved to be more advantageous in terms of both dosage, which was weekly, and efficacy in patients with catheter-related bloodstream infections. ${ }^{[70]}$ Dalbavancin was able to reduce biofilm with $\mathrm{MBC}$ values in the range $1-4 \mathrm{mg} / \mathrm{mL}(0.5-2.2 \mu \mathrm{M})$ in ten MRSA isolates.

\subsubsection{Human kinase inhibitors}

The strategy to repurpose drugs, which have been discovered for the treatment of a particular disorder, to counteract another disease, can be extremely advantageous since their safety profiles are well known and they can be easily obtained for clinical trials. ${ }^{[71]}$

A screening of a library of commercial kinase inhibitors for their antibacterial activity against $S$. aureus and MRSA led to the identification of the anticancer drug sorafenib 17 (Figure 13) as a potent antimicrobial compound effective against MSSA (methicillin-sensitive S. aureus). ${ }^{[72]}$

Derivative 17 was able to inhibit the bacterial growth of $S$. aureus NCTC 8325 and ATCC 12598 with MIC values of $7.6 \mu \mathrm{M}$, eliciting, indeed, no effect on MRSA tested strains ATCC 33592, ATCC 49476 and SCCmec VT.

In order to obtain more potent antibacterial compounds, effective also against MRSA, a library of analogs of compound 16 (Figure 13) was synthesized and tested in vitro and in vivo against $S$. aureus and MRSA infections. Among the new compounds, two derivatives 17 and 18 (Figure 13) showed increased potency against MRSA compared to the lead $16 . .^{[72,73]}$

Compounds 17 and 18 showed against the tested 100 clinical MRSA isolates MIC values in the low micromolar range.

Results highlighted the importance of the 4-chloro-3(trifluoromethyl) phenyl moiety for the antibacterial activity, in 
<smiles>CNC(=O)c1cc(Oc2ccc(NC(=O)Nc3ccc(Cl)c(C(F)(F)F)c3)cc2)ccn1</smiles>

16<smiles>O=C(Nc1ccc(Cl)c(C(F)(F)F)c1)C(CCCl)C(=O)Nc1ccc(Cl)c(C(F)(F)F)c1</smiles>

17<smiles>O=C(Nc1ccc2c(c1)OC(F)(F)O2)Nc1ccc(Cl)c(C(F)(F)F)c1</smiles>

Figure 13. Chemical structure of compounds 16-18.

fact, its replacement with different aliphatic or aromatic groups led to inactive compounds. On the contrary, the aryl heteroaryl ether group was found the portion of the molecule that can be optimized to enhance the antibacterial properties of this class of compounds. In particular, its replacement with the 2,2difluoro-1,3-benzodioxole gave derivative 16 with significantly enhanced MRSA potency ( $\mathrm{MIC}=3 \mu \mathrm{M}$ ). This nucleus proved to play a key role in the anti-MRSA activity, as small structural modifications, including the removal of the fluorine atoms or opening the acetal group, caused the complete loss of the activity. Importantly, compound $\mathbf{1 6}$ showed potent biofilmeradicating activity against the staphylococcal strains killing the persister cells in a concentration- and time-dependent manner eliciting a $\mathrm{BEC}_{50}$ against pre-formed S. aureus ATCC 29213 biofilm of $3.13 \mu \mathrm{M}$ (Figure 14).

The tendency of $\mathbf{1 8}$ to induce bacterial antibiotic resistance was also assayed treating the bacterial cells with different compound concentrations, ranging from 0.25 to 4 -fold MIC, for 27 days. Interestingly, unlike from compound 16 and ofloxacin used as reference antibiotic, which showed rapidly a significant decrease of the activity, compound 18 maintained the same

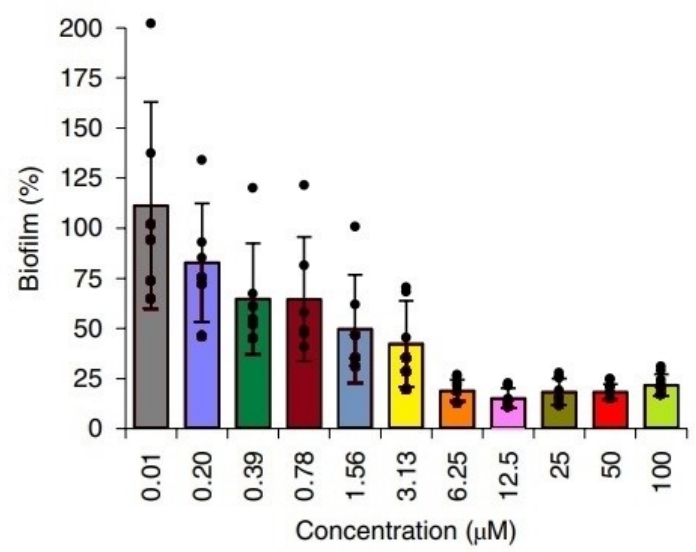

Figure 14. Eradication of S. aureus ATCC 29213 biofilm after treatment (24 h) with different concentrations of compound 18. antibacterial activity during all the treatment. In order to identify the mechanism of action, chemical proteomics studies for the identification of the target were carried out and demethylmenaquinone methyltransferase (MenG), which catalyses the synthesis of the vitamin menaquinone, was recognized as the strongest hit. Inhibition of menaquinone determined the bacterial death since it is involved in the bacterial respiration and energy metabolism.

Based on the high potency and the absence of resistance development, the pharmaceutical profile of derivative 18 was deepened in in vivo studies. To identify the therapeutic window for the in vivo treatment of MRSA infection, was first calculated the ratio between the cytotoxicity against human cell lines $\left(I_{50}\right)$ and the antibacterial activity (MIC), which it was found between 23 to $52 \mu \mathrm{M}$. Additionally, 18 did not induce haemolysis of red blood cells and showed excellent plasma stability.

The in vivo antibacterial efficacy was evaluated in neutropenic mouse model infected with MRSA strain ATCC33591 and treated with $20 \mathrm{mg} / \mathrm{Kg}$ of 18 orally administered. A significant reduction in colony-forming unit (c.f.u./g), up to ten-fold, was observed in comparison the vehicle-treated mice. No toxic effects were revealed for orally and intravenously administrations at dosages of $20 \mathrm{mg} / \mathrm{Kg}$ and $10 \mathrm{mg} / \mathrm{Kg}$, respectively. Moreover, an oral bioavailability of $63 \%$ was found for derivative 18.

\section{Conclusions}

It was established that more than $80 \%$ of the bacterial infections are biofilm-mediated.

The growing knowledge of the staphylococcal biofilm genetics has certainly helped us in the understanding of the complex process of biofilm formation, and have also pointed to potential new therapeutic strategies for serious device-associated infection. ${ }^{[74]}$

However, despite important progresses have been made in this field, many gaps in knowledge are till uncovered due, principally, to the lack of in vivo studies and explanations on 
the mechanisms of action. The individuation of the bacterial target responsible of the anti-biofilm properties of a class of compounds, as well as their validation in a valid in vivo model, were crucial steps for the development of new valuable therapeutic strategies in the struggle against MRSA chronic infections.

The applications of the various anti-biofilm agents change according to the biofilm formation phase on which they interfere. Compounds able to interfere with the biofilm formation should be useful in the prophylaxis to avoid skin or implants biofilm-associated infections caused by MRSA contamination. Dispersal agents could be administered, instead, in association with an antibiotic since they act disrupting the biofilm architecture and then freeing the bacterial cells in their planktonic form.

Eradicating agents represent a valuable strategy to treat established biofilm-associated infections; therefore, they have the potential to become the first-line treatment of chronic MRSA diseases.

Key roles in MRSA biofilm formation were recognized for MSCRAMMs, the major autolysin and eDNA.

Since eDNA is the most common component in MRSA biofilms, whereas PIA is important for a small number of isolates, eDNA can be considered one of the primary target for developing eradication strategies against MRSA biofilms.

Many compounds with interesting anti-biofilm properties and good toxicity profiles were described in the last decade. Nevertheless, the identification of new synthetic small molecules able to eradicate mature MRSA biofilm and to kill persister cells without affecting mammalian cell growth remains an important challenge.

Among them, HPs showed in many cases potent eradication activity against pre-formed MRSA associated with a low toxicity against human cells. HP 7-9 proved to be able to eradicate MRSA biofilms through a non-hemolytic metal(II)-dependent eradicating mechanism of action which demonstrated to be selective towards bacterial cells over mammalian cells. For these features HP scaffold deserves further studies in order to identify the bacterial target and to confirm the anti-biofilm properties in in vivo models.

Noteworthy, the 1-[4-chloro-3-(trifluoromethyl)phenyl]-3(2,2-difluoro-1,3-benzodioxol-5-yl)urea 18 exhibited very interesting results against both planktonic and biofilm forms of MRSA. Interestingly its antibacterial efficacy and its low toxicity were confirmed in in vivo assays. Additionally, compound $\mathbf{1 8}$ is one of the few anti-MRSA biofilm agents for which the mechanism of action has been identified.

Since there are no approved drugs specifically effective against MRSA biofilms in clinical trials to date, further efforts should be made to identify more efficient therapeutic approaches that hopefully target MRSA communities and to deepen the main mechanisms of action as well as the in vivo efficacy.

\section{Conflict of Interest}

The authors declare no conflict of interest.

Keywords: MRSA - biofilms - antibiotic resistance antivirulence $\cdot$ eradicating agents

[1] D. Schillaci, V. Spanò, B. Parrino, A. Carbone, A. Montalbano, P. Barraja, P. Diana, G. Cirrincione, S. Cascioferro, J. Med. Chem. 2017, 60, 82688297.

[2] B. Parrino, D. Carbone, G. Cirrincione, P. Diana, S. Cascioferro, Fut. Med. Chem. 2020, 12, 357-359.

[3] A. Hassoun, P. K. Linden, B. Friedman, Critical Care. 2017, 21, 211.

[4] A. S. Lee, H. de Lencastre, J. Garau, J. Kluytmans, S. Malhotra-Kumar, A. Peschel, S. Harbarth, Nat Rev Dis Primers. 2018, 4, 1-23.

[5] J. Fishovitz, J. A. Hermoso, M. Chang, S. Mobashery, IUBMB Life. 2014, 66, 572-577.

[6] D. L. Popham, K. D. Young, Curr. Opin. Microbiol. 2003, 6, 594-599.

[7] K.-F. Kong, L. Schneper, K. Mathee, APMIS. 2010, 118, 1-36.

[8] D. Lim, N. C. J. Strynadka, Nat. Struct. Biol. 2002, 9, 870-876.

[9] S. Cascioferro, B. Parrino, G. L. Petri, M. G. Cusimano, D. Schillaci, V. Di Sarno, S. Musella, E. Giovannetti, G. Cirrincione, P. Diana, Eur. J. Med. Chem. 2019, 167, 200-210.

[10] R. Sommer, K. Rox, S. Wagner, D. Hauck, S. S. Henrikus, S. Newsad, T. Arnold, T. Ryckmans, M. Brönstrup, A. Imberty, A. Varrot, R.W. Hartmann, A. Titz, J. Med. Chem. 2019, 62, 9201-9216.

[11] A. Carbone, B. Parrino, M. G. Cusimano, V. Spanò, A. Montalbano, P. Barraja, D. Schillaci, G. Cirrincione, P. Diana, S. Cascioferro, Mar. Drugs 2018, 16, 274.

[12] A. R. Kayumov, E. N. Khakimullina, I. S. Sharafutdinov, E. Y. Trizna, L. Z. Latypova, H. Thi Lien, A. B. Margulis, M. I. Bogachev, A. R. Kurbangalieva, The J. Antibiot. 2015, 68, 297-301.

[13] B. Parrino, D. Schillaci, I. Carnevale, E. Giovannetti, P. Diana, G. Cirrincione, S. Cascioferro, Eur. J. Med. Chem. 2019, 161, 154-178.

[14] H.-S. Kim, S.-H. Lee, Y. Byun, H.-D. Park, Sci. Rep. 2015, 5, 8656.

[15] S. Cascioferro, B. Parrino, D. Carbone, D. Schillaci, E. Giovannetti, G. Cirrincione, P. Diana, J. Med. Chem. 2020, 63, 7923-7956.

[16] B. Parrino, P. Diana, G. Cirrincione, S. Cascioferro, Open J. Med. Chem. 2018, 12, 84-87.

[17] F. Fitzpatrick, H. Humphreys, J. P. O'Gara, Clin. Microbiol. Infect. 2005, 11, 967-973.

[18] J. A. Geoghegan, R. M. Corrigan, D. T. Gruszka, P. Speziale, J. P. O'Gara, J. R. Potts, T. J. Foster, J. Bacteriol. 2010, 192, 5663-5673.

[19] C. Pozzi, E. M. Waters, J. K. Rudkin, C. R. Schaeffer, A. J. Lohan, P. Tong, B. J. Loftus, G. B. Pier, P. D. Fey, R. C. Massey, J. P. O'Gara, PLoS Pathog. 2012, 8, e1002626.

[20] E. O'Neill, C. Pozzi, P. Houston, H. Humphreys, D. A. Robinson, A. Loughman, T. J. Foster, J. P. O'Gara, J. Bacteriol. 2008, 190, 3835-3850.

[21] P. Houston, S. E. Rowe, C. Pozzi, E. M. Waters, J. P. O'Gara, Infect. Immun. 2011, 79, 1153-1165.

[22] S. Cascioferro, M. G. Cusimano, D. Schillaci, Fut. Microbiol. 2014, 9, 12091220.

[23] T. J. Foster, J. A. Geoghegan, V. K. Ganesh, M. Höök, Nat Rev Micro. 2014, $12,49-62$.

[24] S. Cascioferro, M. Totsika, D. Schillaci, Microb. Pathog. 2014, 77 C, 105112.

[25] R. Nandakumar, M. P. Nandakumar, M. R. Marten, J. M. Ross, J. Proteome Res. 2005, 4, 250-257.

[26] L. Foulston, A. K. W. Elsholz, A. S. DeFrancesco, R. Losick, mBio 2014, 5, e01667-14.

[27] S. Sugimoto, F. Sato, R. Miyakawa, A. Chiba, S. Onodera, S. Hori, Y. Mizunoe, Sci. Rep. 2018, 8, 2254.

[28] J. M. Yarwood, D. J. Bartels, E. M. Volper, E. P. Greenberg, J. Bacteriol. 2004, 186, 1838-1850.

[29] C. O. Beltrame, M. F. Côrtes, R. R. Bonelli, A. B. de A. Côrrea, A. M. N. Botelho, M. A. Américo, S. E. L. Fracalanzza, A. M. S. Figueiredo, PLoS One. 2015, 10, e0138924.

[30] J. B. Kaplan, E. A. Izano, P. Gopal, M. T. Karwacki, S. Kim, J. L. Bose, K. W. Bayles, A. R. Horswill, mBio 2012, 3, e00198-12.

[31] D. L. Smith, A. D. Harris, J. A. Johnson, E. K. Silbergeld, J. G. Morris, Proc. Natl. Acad. Sci. USA 2002, 99, 6434-6439. 
[32] N. Subrt, L. R. Mesak, J. Davies, J. Antimicrob. Chemother. 2011, 66, 979984.

[33] R. E. Furlani, A. A. Yeagley, C. Melander, Eur. J. Med. Chem. 2013, 62, 5970

[34] T. E. Ballard, J. J. Richards, A. Aquino, C. S. Reed, C. Melander, J. Org. Chem. 2009, 74, 1755-1758.

[35] S. A. Rogers, R. W. Huigens, J. Cavanagh, C. Melander, Antimicrob. Agents Chemother. 2010, 54, 2112-2118.

[36] M. Tadesse, M. B. Strøm, J. Svenson, M. Jaspars, B. F. Milne, V. Tørfoss, J. H. Andersen, E. Hansen, K. Stensvåg, T. Haug, Org. Lett. 2010, 12, 4752-4755.

[37] G. A. Edwards, N. V. Shymanska, J. G. Pierce, Chem. Commun. (Camb.). 2017, 53, 7353-7356.

[38] A. Valliammai, S. Sethupathy, A. Priya, A. Selvaraj, J. P. Bhaskar, V. Krishnan, S. K. Pandian, Sci. Rep. 2019, 9, 13744.

[39] B. R. Boles, A. R. Horswill, PLoS Pathog. 2008, 4, e1000052.

[40] P. Balamurugan, V. Praveen Krishna, D. Bharath, R. Lavanya, P. Vairaprakash, S. Adline Princy, Front. Microbiol. 2017, 8, 1290.

[41] J. McCourt, D. P. O'Halloran, H. McCarthy, J. P. O'Gara, J. A. Geoghegan, FEMS Microbiol. Lett. 2014, 353, 157-164.

[42] Y. Abouelhassan, A. T. Garrison, G. M. Burch, W. Wong, V. M. Norwood, R. W. Huigens, Bioorg. Med. Chem. Lett. 2014, 24, 5076-5080.

[43] H. Mohammad, A.S. Mayhoub, M. Cushman, M. N. Seleem, J Antib. 2015, 68, 259-266.

[44] Y. M. Ibrahim, A. M. Abouwarda, T. Nasr, F. A. Omar, S. Bondock, Microb. Pathog. 2020, 149, 104500.

[45] D. Qu, Z. Hou, J. Li, L. Luo, S. Su, Z. Ye, Y. Bai, X. Zhang, G. Chen, Z. Li, Y. Wang, X. Xue, X. Luo, M. Li, Sci. Adv. 2020, 6, eaay9597.

[46] H.-K. Kang, C. Kim, C. H. Seo, Y. Park, J. Microbiol. 2017, 55, 1-12.

[47] M. G. Cusimano, A. Spinello, G. Barone, D. Schillaci, S. Cascioferro, A. Magistrato, B. Parrino, V. Arizza, M. Vitale, Mar. Drugs 2019, 17, 159.

[48] A. T. Garrison, Y. Abouelhassan, V. M. Norwood, D. Kallifidas, F. Bai, M. T. Nguyen, M. Rolfe, G. M. Burch, S. Jin, H. Luesch, R. W. Huigens, J. Med. Chem. 2016, 59, 3808-3825.

[49] A. T. Garrison, Y. Abouelhassan, D. Kallifidas, F. Bai, M. Ukhanova, V. Mai, S. Jin, H. Luesch, R. W. Huigens, Angew. Chem. Int. Ed. Engl. 2015, 54, $14819-14823$

[50] A. T. Garrison, F. Bai, Y. Abouelhassan, N. G. Paciaroni, S. Jin, R. W. H. lii, RSC Adv. 2014, 5, 1120-1124.

[51] J. J. Harrison, R. J. Turner, D. A. Joo, M. A. Stan, C. S. Chan, N. D. Allan, H. A. Vrionis, M. E. Olson, H. Ceri, Antimicrob. Agents Chemother. 2008 $52,2870-2881$.

[52] D. Schillaci, A. Spinello, M. G. Cusimano, S. Cascioferro, G. Barone, M. Vitale, V. Arizza, World J. Microbiol. Biotechnol. 2016, 32, 124

[53] G. H. De Zoysa, A. J. Cameron, V. V. Hegde, S. Raghothama, V. Sarojini, J. Med. Chem. 2015, 58, 625-639.

[54] H. Yang, Y. Abouelhassan, G. M. Burch, D. Kallifidas, G. Huang, H. Yousaf, S. Jin, H. Luesch, R. W. Huigens, Sci. Rep. 2017, 7, 2003.
[55] A. Basak, Y. Abouelhassan, R. W. Huigens, Org. Biomol. Chem. 2015, 13, 10290-10294.

[56] Y. Abouelhassan, A. T. Garrison, F. Bai, V. M. Norwood, M. T. Nguyen, S. Jin, R. W. Huigens, ChemMedChem. 2015, 10, 1157-1162.

[57] N. El-Najjar, H. Gali-Muhtasib, R. A. Ketola, P. Vuorela, A. Urtti, H. Vuorela, Phytochem. Rev. 2011, 10, 353.

[58] S.-C. Yang, F.-L. Yen, P.-W. Wang, I. A. Aljuffali, Y.-H. Weng, C.-H. Tseng, J.-Y. Fang, Future Microbiol. 2017, 12, 1059-1073.

[59] S.-C. Yang, K.-W. Tang, C.-H. Lin, A. Alalaiwe, C.-H. Tseng, J.-Y. Fang, Front. Microbiol. 2019, 10, 1197.

[60] C. Ghosh, G. B. Manjunath, M. M. Konai, D. S. S. M. Uppu, J. Hoque, K. Paramanandham, B. R. Shome, J. Haldar, PLoS One 2015. 10, e0144094.

[61] W. E. Rose, P. T. Poppens, J. Antimicrob. Chemother. 2009, 63, 485-488.

[62] S. Chopra, K. Harjai, S. Chhibber, J. Antibiot. 2015, 68, 15-22.

[63] S. E. Cramton, C. Gerke, N. F. Schnell, W. W. Nichols, F. Götz, Infect. Immun. 1999, 67, 5427-5433.

[64] Z. Qin, Y. Ou, L. Yang, Y. Zhu, T. Tolker-Nielsen, S. Molin, D. Qu, Microbiol. 2007, 153, 2083-2092.

[65] J. Shi, N.-F. Mao, L. Wang, H.-B. Zhang, Q. Chen, H. Liu, X. Tang, T. Jin, C.T. Zhu, F.-B. Li, L.-H. Sun, X.-M. Xu, Y.-O. Xu, PLoS One 2014, 9, e113133.

[66] M. E. Pachón-lbáñez, S. Ribes, M. A. Domínguez, R. Fernández, F. Tubau, J. Ariza, F. Gudiol, C. Cabellos, Eur. J. Clin. Microbiol. Infect. Dis. 2011, 30, 89-95.

[67] H.-J. Tang, C.-C. Chen, W.-C. Ko, W.-L. Yu, S.-R. Chiang, Y.-C. Chuang, Int. J. Antimicrob. Agents. 2011, 38, 46-51.

[68] J. Perlroth, M. Kuo, J. Tan, A. S. Bayer, L. G. Miller, Arch. Intern. Med. 2008, 168, 805-819.

[69] D. Knafl, S. Tobudic, S. C. Cheng, D. R. Bellamy, F. Thalhammer, Eur. J. Clin. Microbiol. Infect. Dis. 2017, 36, 677-680.

[70] I. Raad, R. Darouiche, J. Vazquez, A. Lentnek, R. Hachem, H. Hanna, B. Goldstein, T. Henkel, E. Seltzer, Clin. Infect. Dis. 2005, 40, 374-380.

[71] N. Nosengo, Nature News. 2016, 534, 314.

[72] H.-C. Chang, Y.-T. Huang, C.-S. Chen, Y.-W. Chen, Y.-T. Huang, J.-C. Su, L.J. Teng, C.-W. Shiau, H.-C. Chiu, J. Antimicrob. Chemother. 2016, 71, 449459.

[73] P. Le, E. Kunold, R. Macsics, K. Rox, M. C. Jennings, I. Ugur, M. Reinecke, D. Chaves-Moreno, M. W. Hackl, C. Fetzer, F. A. M. Mandl, J. Lehmann, V. S. Korotkov, S. M. Hacker, B. Kuster, I. Antes, D. H. Pieper, M. Rohde, W. M. Wuest, E. Medina, S. A. Sieber, Nat. Chem. 2020, 12, 145-158.

[74] E. M. Hetrick, M. H. Schoenfisch, Chem. Soc. Rev. 2006, 35, 780-789.

Manuscript received: August 30, 2020

Revised manuscript received: October 5, 2020

Accepted manuscript online: October 14, 2020

Version of record online: November 6, 2020 